\title{
RENDIMENTO, TEORES DE ÓLEO E PROTEÍNAS DE QUATRO CULTIVARES DE SOJA, PRODUZIDAS EM DOIS LOCAIS NO ESTADO DO MATO GROSSO DO SUL
}

\author{
Yield, oil and protein content of four soybean cultivars produced \\ in two locations of Mato Grosso do Sul State
}

\author{
Andréia Minuzzi', Marco Antônio Sedrez Rangel ${ }^{2}$, Alessandro de Lucca e Braccini ${ }^{1}$, \\ Carlos Alberto Scapim ${ }^{1}$, Freddy Mora ${ }^{1}$, Antonio Dias Robaina ${ }^{3}$
}

\begin{abstract}
RESUMO
Neste trabalho, objetivou-se avaliar o rendimento, teores de óleo e de proteínas nas sementes de quatro cultivares de soja, colhidas em quatro épocas, produzidas em dois locais (Sidrolândia e Dourados) no Estado do Mato Grosso do Sul e em dois anos agrícolas (2004/05 e 2005/06). O delineamento experimental utilizado foi em blocos casualizados com três repetições e tratamentos arranjados no esquema de parcelas subdivididas. As parcelas foram constituídas pelas cultivares de soja (BRS 133, BRS 206, BRS 239 e CD 202) e as subparcelas pelas épocas de colheita ( $R_{7}$ e 7, 14 e 21 dias após o primeiro período). Os dados coletados nos diferentes locais foram submetidos à análise de variância conjunta de parcelas subdivididas e, na presença de interação significativa, foram realizados os desdobramentos necessários para os dois anos agrícolas, separadamente. Avaliaram-se o rendimento de sementes e a determinação de óleo e de proteínas brutas. No ano agrícola 2004/05, em ambos os locais, as cultivares BRS 206, BRS 239 e CD 202 apresentaram as maiores produtividades. No ano agrícola 2005/06, houve diferença significativa entre locais e Sidrolândia obteve maior rendimento que Dourados, para as quatro cultivares avaliadas. O maior teor de proteínas foi observado na cultivar BRS 206 (35\%) e o menor na cultivar CD 202 (31\%). A cultivar CD 202 apresentou o maior teor de óleo (22\%) e a cultivar BRS 206 foi a que apresentou o menor valor (18\%).
\end{abstract}

Termos para indexação: Glycine max (L.) Merrill, produtividade, composição química, colheita.

\section{ABSTRACT}

This study was undertaken to analyze seed yield, oil and protein contents of four soybean cultivars (BRS 133, BRS 206, BRS 239, and CD 202) harvested in two locations of Mato Grosso do Sul state, Brazil (Sidrolândia and Dourados) and in four periods ( $\mathrm{R}_{7}$ and 7, 14, and 21 days after the first period). The crop seasons evaluated corresponded to 2004/2005 and $2005 / 2006$. The experiment was conducted in a randomized complete block design, in a split-plot structure, with three replications. The plots and subplots were constituted of soybean cultivars and harvest periods, respectively. The statistical analysis consisted in analysis of variance, regression analysis and mean testing (Tukey test). Seed yield was measured after maturity of the plants and oil and protein contents were evaluated in both seeds and soybean meal. In the crop season 2004/2005, in both locations, the cultivars BRS 206, BRS 239, and CD 202 showed the largest grain yield. Both oil and protein contents presented low levels that season. In the crop 2005/2006 there were significant differences between locations, Sidrolândia showing better yield than Dourados, for the four cultivars evaluated. BRS 206 cultivar showed the largest protein content, achieving 35\%. The lowest protein content was found in cultivar CD 202, with 31\%. Cultivar CD 202 showed high seed oil content (22\%), while BRS 206 was the cultivar that showed lowest level (18\%).

Index terms: Glycine $\max$ (L.) Merrill, productivity, chemical composition, harvest.

(Recebido em 4 de julho de 2008 e aprovado em 10 de fevereiro de 2009)

\section{INTRODUÇÃO}

No Brasil, nas últimas cinco décadas, a cultura da soja constitui objeto de intensa atividade de pesquisa, com vistas à obtenção de informações que possibilitem expansão de seu cultivo e aumentos na sua produtividade.
Para se obter elevado rendimento por área é indispensável, além de técnicas adequadas de cultivo, a utilização de sementes de boa qualidade e com elevado potencial genético (Braccini, 1993).

A soja é considerada, mundialmente, a principal fonte de produção de óleos e proteínas vegetais para

\footnotetext{
'Doutor, Professor Associado - Departamento de Agronomia - Universidade Estadual de Maringá - Av. Colombo 5790, Bloco J-45 - $87020-900$ - Maringá PR. E-mail: andminuzi@zipmail.com.br; albraccini@uol.com.br; cascapim@uem.br; fmora@universiabrasil.net

2Doutor, Pesquisador - Empresa Brasileira de Pesquisa Agropecuária - Embrapa Mandioca e Fruticultura Tropical - Caixa Postal 007 - $44380-000$ - Cruz das Almas, BA. E-mail: rangel@cnpmf.embrapa.br.

${ }^{3}$ Doutor, Professor - Departamento de Ciências Agrárias - Universidade Federal da Grande Dourados - km 12 Rod. Dourados-Itahum - $79804-970$ Dourados, MS. E-mail: robaina@ceud.ufgd.br.
} 
alimentação humana e animal (Manara, 1988). Constitui, atualmente, um dos produtos de maior importância na economia brasileira, ocupando lugar de destaque na oferta de óleo para consumo interno, no arraçoamento animal como principal fonte protéica, bem como, na pauta de exportações do país, como geradora de divisas. Em razão da grande importância, procurase aumentar sua produção por meio de incremento da área de plantio e/ou do rendimento por área (Sediyama et al., 1993).

Os trabalhos de melhoramento visam a obter cultivares que, associados aos teores de óleo e proteína elevados, apresentem bom rendimento de grãos. As correlações negativas entre os teores de óleo, proteína e rendimento de grãos têm dificultado o progresso do melhoramento. A princípio, os teores de óleo e proteína das sementes de soja são governados geneticamente, porém, fortemente influenciados pelo ambiente, principalmente durante o período de enchimento dos grãos. Essa influência ambiental carece de estudos mais detalhados, em razão das várias interações possíveis (Pípolo, 2002).

No Brasil, nos últimos anos, são frequentes os questionamentos, em alguns estados brasileiros, principalmente pela indústria de moagem de grãos, sobre a redução do teor de proteínas dos grãos de soja que chegam à indústria. Os teores de proteínas e óleo de grãos de soja podem variar em função da genética do material, do local no qual é cultivado e pela forma de manejo da cultura, porém não existem estudos conclusivos sobre a correlação existente entre estes fatores e a qualidade e produtividade da soja (Pípolo, 2002).

Nesse intuito, conduziu-se o presente trabalho, com o objetivo de avaliar o rendimento, os teores de óleo e de proteínas nas sementes de quatro cultivares de soja, colhidas em quatro épocas, produzidas em dois locais no Mato Grosso do Sul e em dois anos agrícolas.

\section{MATERIALE MÉTODOS}

O experimento de campo foi instalado em área localizada no município de Sidrolândia - MS (2100'S, $55^{\circ} 00^{\prime} \mathrm{W}$, com altitude $470 \mathrm{~m}$ ), pertencente à Fazenda Recanto e em outra área experimental localizada no município de Dourados - MS (22 $16^{\prime} \mathrm{S}, 54^{\circ} 49^{\prime} \mathrm{W}$, com altitude $450 \mathrm{~m}$ ), pertencente a Sementes Guerra S/A, nos anos agrícolas de 2004/05 e 2005/06.

Os dados de precipitação pluvial, temperaturas máxima e mínima diárias, referentes aos períodos de duração do experimento a campo, foram coletados diariamente e estão ilustrados na Figura 1. O solo dos dois locais é caracterizado como Latossolo Vermelho distroférrico (Embrapa, 1999). Na adubação de semeadura dos dois anos agrícolas em Sidrolândia e Dourados, utilizou-se $400 \mathrm{~kg} \mathrm{ha}^{-1} \mathrm{da}$ fórmula 2-20-20. A semeadura foi efetuada de forma direta, em palhada de aveia, semeada no período de inverno e dessecada com Glyphosate, na dose de $4 \mathrm{~L} \mathrm{ha}^{-1}$ (1440 $\mathrm{g}_{\text {i.a ha }}{ }^{-1}$ ), 30 dias antes da semeadura da soja.

$\mathrm{O}$ delineamento experimental foi em blocos casualizados com três repetições de campo e tratamentos arranjados no esquema de parcelas subdivididas. As parcelas foram constituídas por quatro cultivares de soja (BRS 133, BRS 206, BRS 239 e CD 202), em dois locais de instalação (Dourados e Sidrolândia - MS) e dois anos agrícolas 2004/05 e 2005/ 06. As subparcelas foram constituídas de quatro épocas de colheita $\left(R_{7}\right.$, sete, quatorze e vinte e um dias após a primeira época).

$\mathrm{O}$ ensaio foi instalado utilizando-se quatro genótipos de soja: CD 202, BRS 239, BRS 206 (ciclo precoce) e BRS 133 (ciclo semiprecoce). A semeadura foi realizada no segundo decêndio de novembro que é a época preferencial. Para a homogeneização da população de plantas, foram utilizadas quantidades maiores de sementes que a indicada. Duas semanas após a emergência das plantas, foram realizados desbastes, deixando-se cerca de 14 plantas por metro linear, com $0,45 \mathrm{~m}$ entre fileiras e densidade de 311.111 plantas $\mathrm{ha}^{-1}$. As sementes foram tratadas com fungicida à base de Carboxin + Thiram, na dose de $250 \mathrm{~mL}$ do produto comercial $+250 \mathrm{~mL}$ de água para cada $100 \mathrm{~kg}$ de sementes, como também inoculadas com inoculante turfoso à base de Bradyrhizobium japonicum. Tanto em Sidrolândia como em Dourados, os tratos culturais foram realizados, conforme as indicações da região até o final do ciclo da cultura (Embrapa, 2004).

As parcelas (cultivares de soja) foram constituídas de oito fileiras de 10 metros de comprimento, espaçadas de 0,45 m entre si para os genótipos de soja. Na colheita das subparcelas (épocas de colheita), foram eliminadas as fileiras externas, bem como $2,5 \mathrm{~m}$ de cada extremidade das fileiras centrais como bordaduras e colhidas parcelas de duas fileiras com cinco metros de comprimento. A área útil das unidades experimentais foi de $4,5 \mathrm{~m}^{2}$. A colheita foi realizada em quatro épocas: no estádio $R_{7}$ (Fehr et al., 1971) e aos sete, 14 e 21 dias após a 1o época.

Avaliou-se o rendimento das sementes e a composição química avaliada pela determinação de óleo e de proteínas brutas, que são descritos a seguir:

Rendimento de sementes: partindo-se do rendimento de grãos nas subparcelas, foram calculadas 

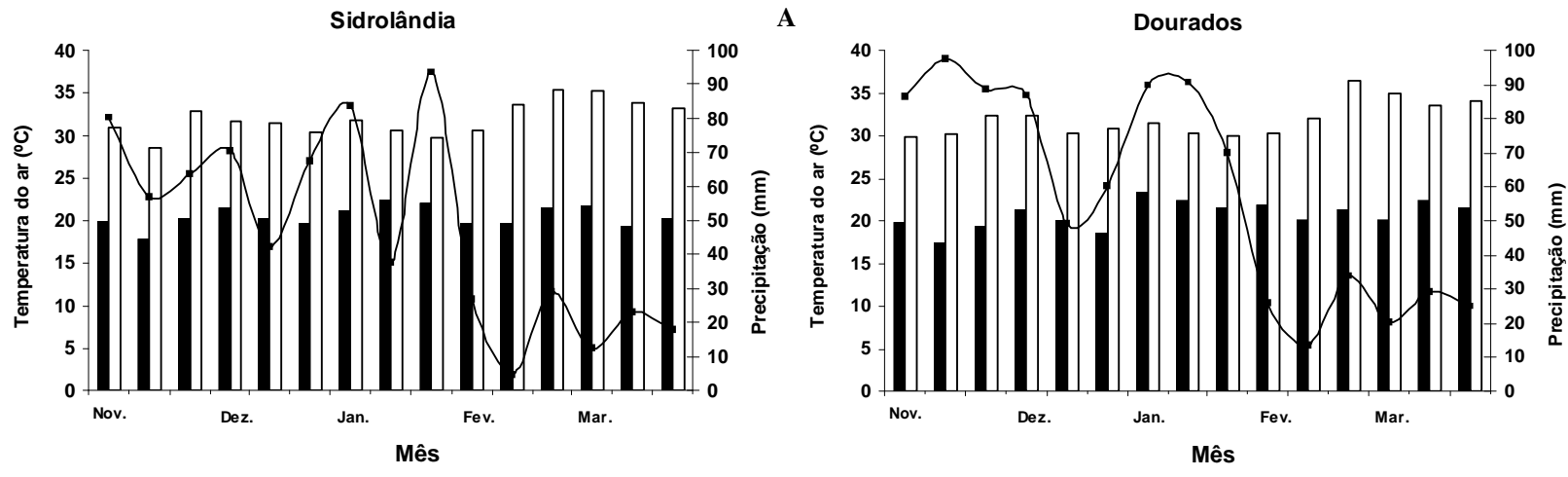

- Temperatura mínima $\square$ Temperatura máxima $\rightarrow$ Precipitação
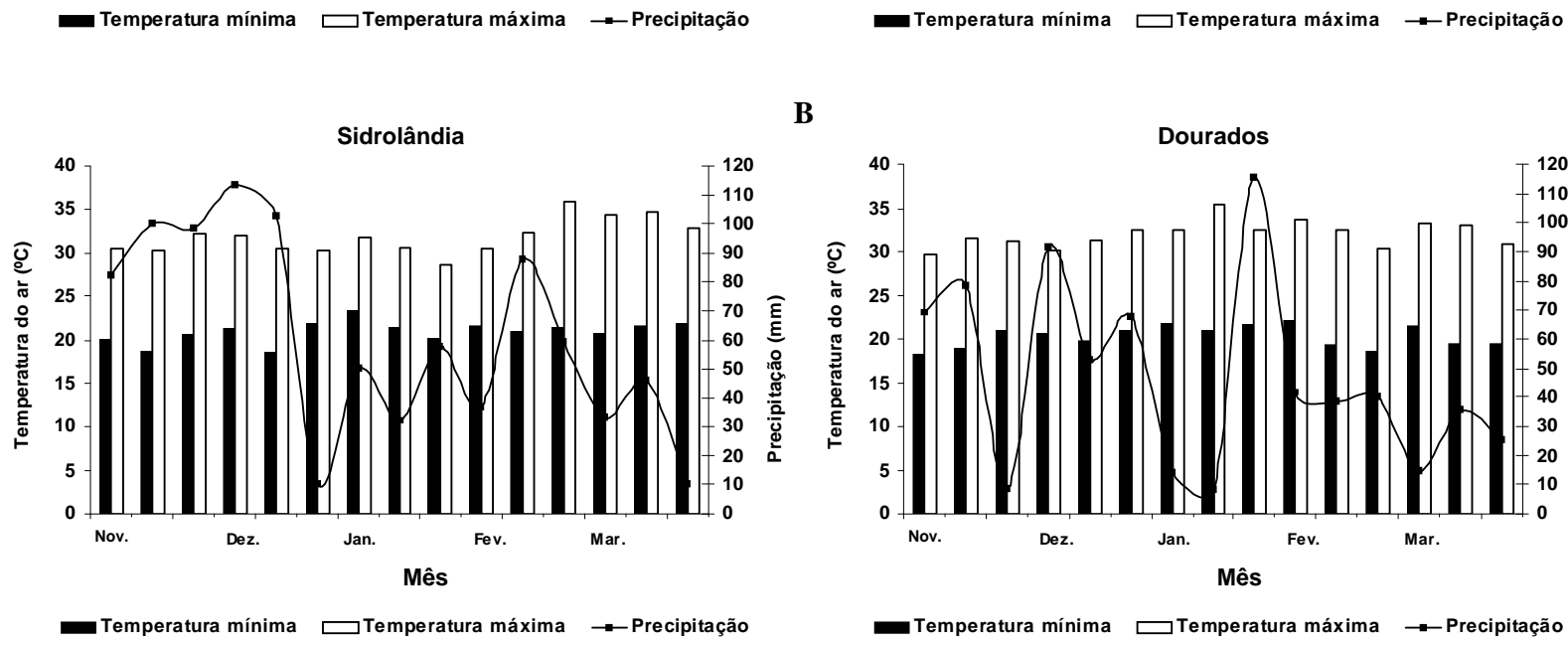

B

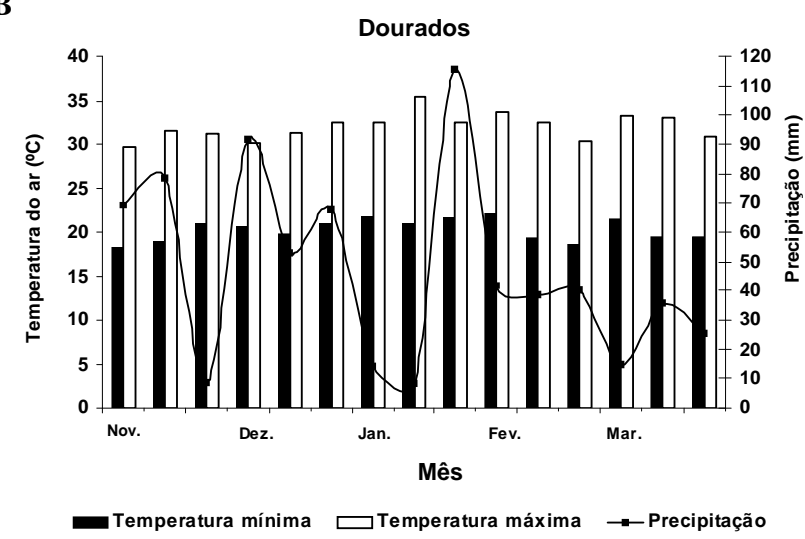

Figura 1 - Dados de temperaturas mínima e máxima e precipitação pluvial, em Sidrolândia e Dourados, MS, de novembro a março, nos anos agrícolas de 2004/05 (A) e 2005/06 (B).

as produtividades em $\mathrm{kg} \mathrm{ha}^{-1}$. $\mathrm{O}$ dados de produtividade de grãos foram corrigidos para $13 \%$ de umidade (base úmida). $\mathrm{O}$ grau de umidade das sementes foi avaliado por meio do método de estufa a $105^{\circ} \mathrm{C}$ por 24 horas (Brasil, 1992).

Determinação de óleo: foi realizada segundo o procedimento descrito nas Normas Analíticas do Instituto Adolfo Lutz (1985).

Determinação de proteínas brutas: foi realizada conforme a recomendação da Association of Official Analytical Chemists (AOAC, 1975) e Vitti et al. (2001).

Posteriormente, os dados coletados foram submetidos à análise de variância conjunta de parcelas subdivididas e, na presença de interação significativa, foram realizados os desdobramentos necessários. As médias das cultivares de soja foram comparadas pelo teste de Tukey e análise de regressão, em função das épocas de colheita, para cada genótipo, em nível de 5\% de probabilidade, considerando, para tanto, efeito significativo na análise de variância. Para o efeito de local, o teste $\mathrm{F}$ foi conclusivo, com apenas um grau de liberdade.

\section{RESULTADOS E DISCUSSÃO}

\section{Ano agrícola 2004/05}

A análise de variância conjunta das características avaliadas revelou efeito significativo $(\mathrm{p}<0,05)$ apenas para o efeito principal local (REND), cultivar (ÓLEO e PROT) e para a interação de primeira ordem local x cultivar (REND) (Tabela 1). Para nenhuma das variáveis resposta, ocorreu efeito significativo $(\mathrm{p}<0,05)$ para época, tanto para efeito principal, quanto nas interação. Somente na presença da interação significativa, procederam-se os desdobramentos necessários. O efeito principal época, como as interações envolvendo o fator época de colheita, não apresentaram diferença significativa $(\mathrm{p}<0,05)$, portanto, as variáveis avaliadas não responderam ao efeito da colheita em diferentes épocas. 
Tabela 1 - Análise de variância referente ao rendimento (REND), determinação de óleo (ÓLEO) e determinação de proteínas (PROT), de quatro cultivares de soja, produzidas em quatro épocas de colheita, em Sidrolândia e Dourados, MS, no ano agrícola de 2004/05.

\begin{tabular}{lcccc}
\hline \multirow{2}{*}{ Fontes de Variação } & G.L. & \multicolumn{3}{c}{ Quadrados Médios } \\
\cline { 3 - 5 } & 1 & $1705333,5^{*}$ & ÓLEO $(\%)$ & PROT $(\%)$ \\
\hline Local & 3 & $2009304 \mathrm{~ns}$ & $14,3 \mathrm{~ns}$ & $14,3 \mathrm{~ns}$ \\
Cultivar & 3 & $157459,7^{*}$ & $6,7 \mathrm{~ns}$ & $125,9^{*}$ \\
Local*Cultivar & 4 & 8094,9 & $15,6 \mathrm{~ns}$ & $6,7 \mathrm{~ns}$ \\
Blocos (Local) & 12 & 9869,5 & 16,6 & $15,6 \mathrm{~ns}$ \\
Erro 1 & 3 & $13121,0 \mathrm{~ns}$ & $17,7 \mathrm{~ns}$ & 16,6 \\
Época & 9 & $6738,9 \mathrm{~ns}$ & $11,2 \mathrm{~ns}$ & $17,7 \mathrm{~ns}$ \\
Cul.* Epo. & 3 & $13255,9 \mathrm{~ns}$ & $13,0 \mathrm{~ns}$ & $11,2 \mathrm{~ns}$ \\
Loc.*Epo. & 9 & $7606,6 \mathrm{~ns}$ & $19,6 \mathrm{~ns}$ & $13,0 \mathrm{~ns}$ \\
Loc.*Cul.*Epo & 48 & 7694,8 & 17,7 & $19,6 \mathrm{~ns}$ \\
Erro 2 & & 2112,1 & 33,5 & 17,7 \\
\hline Média geral & & 4,7 & 12,2 & 33,5 \\
\hline CV 1 (\%) & 4,1 & 12,6 & 12,2 \\
CV 2 (\%) & & & 12,6 \\
\hline
\end{tabular}

*Significativo a $5 \%$ de probabilidade, pelo teste F; ns - Não significativo.

Efeito das cultivares dentro de locais e de locais dentro das cultivares

Em Sidrolândia e em Dourados, as cultivares BRS 206, BRS 239 e CD 202 foram as que apresentaram maiores produtividades, não diferindo entre si e a BRS 133 foi a que apresentou o menor rendimento (Tabela 2).

O uso de sementes de melhor qualidade para a semeadura, aliado à ocorrência de condições climáticas adequadas, constitui-se em um fator de extrema importância na obtenção de um estabelecimento adequado de plantas no campo e maiores rendimentos por unidade de área. Desta forma, qualquer condição que leve a um baixo estande de plantas acarretará em maiores custos de produção e menores lucros. A redução no volume de chuva em fevereiro e março afetou a produtividade, pois as plantas que estavam em fase de desenvolvimento das vagens ou de enchimento de grãos foram obrigadas a abortar ou produziram grãos menores. Segundo Fietz \& Urchei (2002), a ocorrência de déficit hídrico é uma das principais causas de perdas agrícolas na região de Dourados, MS, pois na safra de verão ocorrem frequentemente veranicos e estiagens, em virtude da grande evapotranspiração e distribuição irregular das chuvas.
Tabela 2 -Médias obtidas do rendimento de sementes em kg ha $^{-1}$ (REND), de quatro cultivares de soja, em Sidrolândia e Dourados, MS, no ano agrícola de 2004/05.

\begin{tabular}{ccc}
\hline \multicolumn{2}{c}{ Cultivares $^{1}$} & \multicolumn{2}{c}{ Local $^{2}$} \\
\hline BRS 133 & Sidrolândia & Dourados \\
BRS 206 & 1586 b B & 1941 b A \\
BRS 239 & 1773 a B & 2194 a A \\
CD 202 & 2320 a A & 2371 a A \\
\hline Média & 2234 a A & 2475 a A \\
\hline
\end{tabular}

${ }^{1}$ Médias seguidas de mesma letra minúscula na coluna não diferem entre si pelo teste de Tukey, a 5\% de probabilidade. ${ }^{2}$ Médias seguidas de mesma letra maiúscula na linha não diferem entre si pelo teste $\mathrm{F}$, a $5 \%$ de probabilidade.

\section{Efeito principal de local}

Na Tabela 2, em média, observa-se que a região de Dourados apresentou maior produtividade $\left(2245 \mathrm{~kg} \mathrm{ha}^{-1}\right)$. Em ambas as regiões, ocorreu estresse hídrico durante os estádios de enchimento de grãos, com alta umidade relativa oscilante e elevadas temperaturas. Esses resultados condizem com Hanson (1992) que, a partir de resultados de três anos, verificou que genótipos com maiores períodos reprodutivos e de enchimento de sementes obtiveram maior 
produtividade em condições favoráveis. Porém, na ocorrência de estresse hídrico durante o período reprodutivo, essa vantagem não foi verificada. Em condições de estresses hídricos, os processos de macrosporogênese e microsporogênese não ocorrem, tendo como consequência, o aparecimento de plantas totalmente estéreis. Sobre estresse hídrico não há germinação do grão de pólen ou formação do tubo polínico, impedindo a fertilização do óvulo e, consequentemente, a formação da semente (Embrapa, 2004). Segundo Moterle et al. (2008), o estresse hídrico reduziu todas as variáveis analisadas em sementes de milho-pipoca. As últimas semanas apresentaram índice muito baixo de pluviosidade e temperaturas elevadas, o que pode significar o comprometimento da maturação fisiológica da soja. Com a falta de chuvas e a elevação de temperatura, provavelmente ocorreram prejuízos na parte aérea da planta, resultando na produção de grãos leves ou mal formados.

\section{Efeito principal de cultivar}

As cultivares BRS 133 e BRS 206 não apresentaram diferenças significativas entre si e obtiveram as maiores porcentagens de proteínas, seguidas pela cultivar BRS 239 e a cultivar CD 202 apresentou a menor porcentagem de proteínas (Tabela 3).

$\mathrm{Na}$ determinação do óleo, as cultivares apresentaram efeito inverso em relação ao teor de proteínas, em que a cultivar CD 202 apresentou a maior porcentagem de óleo, diferindo das demais cultivares. As cultivares BRS $133 \mathrm{e}$ BRS 206 não apresentaram diferenças significativas entre si e apresentaram os menores teores de óleo (Tabela 3). Altas temperaturas durante o desenvolvimento das sementes estão associadas com a redução no teor de óleo total, porém em condições de campo, esse efeito é variável de acordo com outros fatores ambientais, tais como o estresse hídrico que influencia a produção de óleo, por meio de seus efeitos sobre o crescimento e o desenvolvimento da semente (Harris et al., 1978).

Os valores de proteínas e óleo estão semelhantes aos apresentados normalmente, e a baixa produção desses dois componentes por hectare foi em função da baixa produtividade. A variabilidade e as mudanças globais no clima e a composição atmosférica podem e, frequentemente, mudam o comportamento da cultura da soja, apresentando efeitos sobre a quantidade e qualidade das sementes colhidas, influenciando nos principais componentes da semente: óleo, proteínas e carboidratos (Bordignon et al., 2006).

\section{Ano agrícola 2005/06}

A análise de variância conjunta das características avaliadas revelou efeito significativo $(\mathrm{p}<0,05)$ apenas para o efeito principal local (REND), cultivar (REND, ÓLEO e
Tabela 3 - Médias obtidas na determinação de óleo (ÓLEO) e na determinação de proteínas (PROT), das sementes de quatro cultivares de soja em Sidrolândia e Dourados, MS, no ano agrícola de 2004/05.

\begin{tabular}{ccc}
\hline \multirow{2}{*}{ Cultivares } & \multicolumn{2}{c}{ Características } \\
\cline { 2 - 3 } & ÓLEO $(\%)$ & PROT $(\%)$ \\
\hline BRS 133 & $19 \mathrm{c}$ & $35 \mathrm{a}$ \\
BRS 206 & $18 \mathrm{c}$ & $35 \mathrm{a}$ \\
BRS 239 & $20 \mathrm{~b}$ & $32 \mathrm{~b}$ \\
CD 202 & $22 \mathrm{a}$ & $30 \mathrm{c}$ \\
\hline Média & 20 & 33
\end{tabular}

Médias seguidas de mesma letra, na coluna, não diferem entre si pelo teste de Tukey, a $5 \%$ de probabilidade.

PROT) e a interação de primeira ordem local x cultivar (REND) (Tabela 4). Somente na presença da interação significativa, procederam-se os desdobramentos necessários. Como no ano anterior, para 2005/06, o efeito principal época, como as interações envolvendo o fator época de colheita, não apresentaram diferença significativa $(\mathrm{p}<0,05)$, portanto, as variáveis avaliadas não responderam ao efeito da colheita em diferentes épocas.

\section{Efeito das cultivares dentro de locais e de locais dentro das cultivares}

Ao analisar os dados apresentados na Tabela 5, percebe-se que as cultivares não apresentaram diferença significativa de rendimento nos dois locais. Houve diferença significativa entre locais, e Sidrolândia apresentou melhores condições climáticas e, consequentemente, maior rendimento que Dourados, para as quatro cultivares avaliadas. A média de rendimento para Sidrolândia foi de $4161 \mathrm{~kg} \mathrm{ha}^{-1} \mathrm{e}$ para Dourados $2836 \mathrm{~kg} \mathrm{ha}^{-1}$. Em virtude de desequilíbrios ambientais, como é o caso do aquecimento global, modificações nítidas no clima vêm sucedendo-se com certa frequência, associadas a eventos antes atípicos ou da menor intensidade, como é o caso de secas prolongadas e severas (Keinski \& Feijó, 2005).

Vários autores citam a influência de fenômenos e mecanismos atmosféricos como o El Niño e a La Niña e, possivelmente, outros de ocorrência esporádica, mas por vezes repetida ao longo do tempo. Influência essa, verificada e nítida no clima e, por consequência, no crescimento, desenvolvimento e produção das culturas, confirmando, por exemplo, a influência da precipitação pluvial na produtividade de sementes e, também, na qualidade das sementes de soja, para os subperíodos vegetativo e reprodutivo, que correspondem aos meses de final da primavera a final de verão (Berlato \& Fontana, 1999). 
Tabela 4 - Análise de variância referente ao rendimento (REND), determinação de óleo (ÓLEO) e determinação de proteínas (PROT), nas sementes de quatro cultivares de soja, produzidas em quatro épocas de colheita, em Sidrolândia e Dourados, MS, no ano agrícola de 2005/06.

\begin{tabular}{|c|c|c|c|c|}
\hline \multirow{2}{*}{ Fontes de Variação } & \multirow{2}{*}{ G.L. } & \multicolumn{3}{|c|}{ Quadrados Médios } \\
\hline & & $\operatorname{REND}\left(\mathrm{kg} \mathrm{ha}^{-1}\right)$ & ÓLEO (\%) & PROT $(\%)$ \\
\hline Local & 1 & $42132350 *$ & $0,2 \mathrm{~ns}$ & $0,3 \mathrm{~ns}$ \\
\hline Cultivar & 3 & $1352986 *$ & $68,6 *$ & $89,3 *$ \\
\hline Local*Cultivar & 3 & $143060 *$ & $0,1 \mathrm{~ns}$ & $0,1 \mathrm{~ns}$ \\
\hline Blocos (Local) & 4 & 270688 & 1,2 & 1,5 \\
\hline Erro 1 & 12 & 98964 & 0,9 & 1,1 \\
\hline Época & 3 & $174935 \mathrm{~ns}$ & $1,4 \mathrm{~ns}$ & $1,7 \mathrm{~ns}$ \\
\hline Cul.*Epo. & 9 & $163318 \mathrm{~ns}$ & $0,6 \mathrm{~ns}$ & $0,9 \mathrm{~ns}$ \\
\hline Loc.*Epo. & 3 & $38424 \mathrm{~ns}$ & $1,2 \mathrm{~ns}$ & $0,3 \mathrm{~ns}$ \\
\hline Loc. ${ }^{*}$ Cul. ${ }^{*}$ Epo & 9 & $64617 \mathrm{~ns}$ & $1,0 \mathrm{~ns}$ & $2,5 \mathrm{~ns}$ \\
\hline Erro 2 & 48 & 65263 & 1,5 & 2,2 \\
\hline Média geral & & 3498,8 & 20,5 & 33,4 \\
\hline CV $1(\%)$ & & 8,9 & 4,6 & 3,1 \\
\hline CV $2(\%)$ & & 7,3 & 5,9 & 4,4 \\
\hline
\end{tabular}

*Significativo a $5 \%$ de probabilidade, pelo teste F; ns - Não significativo.

Tabela 5 - Médias obtidas do rendimento de sementes em $\mathrm{kg} \mathrm{ha}^{-1}$ (REND) de quatro cultivares de soja, em Sidrolândia e Dourados, MS, no ano agrícola de 2005/06.

\begin{tabular}{ccc}
\hline \multirow{2}{*}{ Cultivares $^{1}$} & \multicolumn{2}{c}{ Local $^{2}$} \\
\cline { 2 - 3 } & Sidrolândia & Dourados \\
\hline BRS 133 & 4548 a A & 3015 a B \\
BRS 206 & 4251 a A & 2906 a B \\
BRS 239 & 3847 a A & 2605 a B \\
CD 202 & 3997 a A & 2818 a B \\
\hline Média & 4161 A & 2836 B
\end{tabular}

${ }^{1}$ Médias seguidas de mesma letra minúscula na coluna não diferem entre si pelo teste de Tukey, a 5\% de probabilidade.

${ }^{2}$ Médias seguidas de mesma letra maiúscula na linha não diferem entre si pelo teste $\mathrm{F}$, a $5 \%$ de probabilidade.

\section{Efeito principal de local}

A produtividade da soja foi maior em Sidrolândia (4161 kg ha-1) que em Dourados (2836 kg ha' ${ }^{-1}$ ) apresentando diferença significativa $(p>0,05)$, entre os dois locais avaliados (Tabela 5). Em Sidrolândia, a precipitação foi superior a Dourados; isto influenciou no desenvolvimento da cultura, principalmente em virtude de a deficiência hídrica ter sido mais prejudicial na região de Dourados. O efeito da deficiência hídrica na produção depende da época de ocorrência e de sua severidade. Para a cultura da soja, a fase reprodutiva é a mais crítica. No florescimento, causa o abortamento das flores e impede a antese, enquanto, no enchimento dos grãos, afeta a massa das sementes e, consequentemente, a produção (Fageria, 1989).

\section{Efeito principal de cultivar}

No rendimento de sementes, a cultivar BRS 133 apresentou maior produtividade $\left(3782 \mathrm{~kg} \mathrm{ha}^{-1}\right.$ ) que a BRS 239 (3226 kg ha $\left.{ }^{-1}\right)$. As cultivares BRS 206 e CD 202 apresentaram comportamento intermediário, não diferindo das demais (Tabela 5). A deficiência hídrica afeta o metabolismo e prejudica o crescimento das plantas, o que acarreta menor suprimento de assimilados, sendo, o período de enchimento de grãos o mais crítico para a soja (Marcos Filho, 2005). As diferenças de data de floração entre anos, apresentadas por uma cultivar semeada numa mesma época, são por causa das variações de temperatura. Assim, a floração precoce ocorre, principalmente, em decorrência de altas temperaturas, podendo acarretar diminuição na altura da planta. Esse problema pode se agravar se, paralelamente, houver insuficiência hídrica e/ou fotoperiódica durante a fase de crescimento. Por outro lado, diferenças de data de floração entre cultivares, numa mesma época de semeadura são por causa, principalmente, à resposta diferencial das cultivares ao comprimento do dia (Embrapa, 2004).

Os teores de proteínas obtidos foram de 35, 34, 32 e $31 \%$ para as cultivares BRS 206, BRS 133, BRS 239 e CD 202 , respectivamente. Todas apresentaram diferença 
estatística ( $p>0,05)$ entre si. Taiz \& Zeiger (2004), discorrendo sobre a fisiologia do estresse, comentam os efeitos perniciosos da associação estresse por calor e o choque térmico, com estresse por déficit hídrico. A temperatura da folha que transpira ativamente, em geral, é mais baixa do que a temperatura do ar, mas o déficit hídrico, quando associado, restringe à transpiração e causa superaquecimento e agrava o estresse pelo calor. $\mathrm{O}$ estresse pelo calor inibe a fotossíntese e prejudica a função de membranas e a estabilidade protéica (Marcos Filho, 2005). Informações dessa natureza podem contribuir na elucidação das causas do comportamento diferencial entre as cultivares, quando expostas a altas temperaturas, ou outras situações estressantes.

Os teores de óleo foram de 22, 20,19 e 18\% para as cultivares CD 202, BRS 239, BRS 133 e BRS 206, respectivamente (Tabela 6). À medida que se aumenta o teor de proteínas, o teor de óleo é reduzido, comprovando a correlação negativa entre essas duas características. Vários autores relataram a correlação negativa existente entre proteínas e óleo. Helms \& Orf (1999) mostraram que a seleção direta para o teor de proteínas produziu redução no teor de óleo. Segundo Sediyama et al. (1993), os níveis de proteínas nas sementes de soja variam de 30 a $46 \%$ e os de óleo de 12 a $24 \%$, em virtude dos efeitos do local e das cultivares.

Tabela 6 - Médias obtidas no rendimento de sementes (REND), na determinação de óleo (ÓLEO) e na determinação de proteínas (PROT), das sementes de quatro cultivares de soja, em Sidrolândia e Dourados, MS, no ano agrícola de 2005/06.

\begin{tabular}{cccc}
\hline \multirow{2}{*}{ Cultivar } & \multicolumn{3}{c}{ Características } \\
\cline { 2 - 4 } & $\begin{array}{c}\text { REND } \\
\left(\mathrm{kg} \mathrm{ha}^{-1}\right)\end{array}$ & ÓLEO $(\%)$ & PROT (\%) \\
\hline BRS 133 & $3782 \mathrm{a}$ & $19 \mathrm{c}$ & $34 \mathrm{~b}$ \\
BRS 206 & $3578 \mathrm{ab}$ & $18 \mathrm{~d}$ & $35 \mathrm{a}$ \\
BRS 239 & $3226 \mathrm{~b}$ & $20 \mathrm{~b}$ & $32 \mathrm{c}$ \\
CD 202 & $3407 \mathrm{ab}$ & $22 \mathrm{a}$ & $31 \mathrm{~d}$ \\
\hline Média Geral & 3498 & 20 & 33 \\
\hline
\end{tabular}

Médias seguidas de mesma letra, em cada coluna, não diferem entre si pelo teste de Tukey, a 5\% de probabilidade.

\section{CONCLUSÕES}

Mediante os resultados obtidos na realização deste trabalho, conclui-se que:

\section{Ano agrícola 2004/05}

Em Sidrolândia e em Dourados, as cultivares BRS 206, BRS 239 e CD 202, foram as que apresentaram maiores produtividades não diferindo entre si e a BRS 133 foi a que apresentou o menor rendimento.

\section{Ano agrícola 2005/06}

As quatro cultivares avaliadas não diferiram entre si em relação ao rendimento. Em Sidrolândia, o rendimento das cultivares foi superior aos obtidos em Dourados.

O maior teor de proteínas foi observado na cultivar BRS 206 (35\%) e o menor teor na cultivar CD $202(31 \%)$. A cultivar CD 202 apresentou o maior teor de óleo (22\%) e a cultivar BRS 206 foi a que apresentou o menor valor (18\%).

\section{REFERÊNCIAS BIBLIOGRÁFICAS}

ASSOCIATION OF OFFICIAL ANALYTICAL CHEMISTS. Official methods of analysis. Washington, DC, 1975. 1054p.

BERLATO, M.A.; FONTANA, D.C. Variabilidade interanual da precipitação pluvial e rendimento da soja no estado do Rio Grande do Sul. Revista Brasileira de Agrometeorologia, Santa Maria, v.7, n.1, p.119-125, 1999.

BORDIGNON, J.R.; LONG, S.P.; ENGESETH, N.J.

Influência da composição atmosférica no comportamento da cultura da soja. In: CONGRESSO BRASILEIRO DE SOJA, 4., 2006, Londrina. Anais... Londrina: Embrapa-CNPSo, 2006. p.70-73.

BRACCINI, A.L. Avaliação da qualidade fisiológica da semente de linhagens e variedade de soja com diferentes graus de impermeabilidade do tegumento. 1993. 109f. Dissertação (Mestrado)-Universidade Federal de Viçosa, Viçosa, MG, 1993.

BRASIL. Ministério da Agricultura e Reforma Agrária. Regras para análise de sementes. Brasília, DF: SNAD/ DNDV/CLAV, 1992. 365p.

EMPRESA BRASILEIRA DE PESQUISA BRASILEIRA. Sistema brasileiro de classificação dos solos. Brasília, DF, 1999. 412p.

EMPRESA BRASILEIRA DE PESQUISA BRASILEIRA. Tecnologias de produção de soja: região Central do Brasil. Londrina: Fundação Meridional, 2004. 239p.

FAGERIA, N.K. Solos tropicais e aspectos fisiológicos das culturas. Brasília, DF: Embrapa-CNPAF, 1989. 392p. 
FEHR, W.R.; CAVINESS, C.E.; GURMOOD, D.T.; PENNINGTON, J.S. Stage of development description for soybean, Glycine $\max$ (L.) Merril. Crop Science, Madison, v.11, n.6, p.929-931, 1971.

FIETZ, C.R.; URCHEI, M.A. Deficiência hídrica da cultura da soja na Região de Dourados, MS. Revista Brasileira de Engenharia Agrícola e Ambiental, Campina Grande, v.6, n.2, p.262-265, 2002.

HANSON, W.D. Modified seed maturation and seed yield potentials in soybean. Crop Science, Madison, v.32, n.4, p.972-976, 1992.

HARRIS, H.C.; McWILLIAMS, J.R.; MASON, W.K. Influence of temperature on oil content and composition of sunflower seed. Australian Journal of Agricultural Research, Collingngwood, v.29, n.3, p.1203-1212, 1978.

HELMS, T.C.; ORF, J.H. Protein, oil and yield of soybean lines selected for increased protein. Crop Science, Madison, v.38, p.707-711, 1999.

INSTITUTO ADOLFO LUTZ. Normas analíticas do Instituto Adolfo Lutz: métodos químicos e físicos para análise de alimentos. São Paulo, 1985. v.1, 533p.

KEINSKI, R.; FEIJÓ, B.V. O começo do fim, a humanidade está diante da maior ameaça de todos os tempos: o aquecimento global. Super Interessante, São Paulo, n.218, p.44-54, out. 2005.

MANARA, N.T.F. Origem e expansão. In: SANTOS, O.S. (Coord.). A cultura da soja 1, Rio grande do Sul, Santa Catarina e Paraná. Rio de Janeiro: Globo, 1988. p.13-23.

MARCOS FILHO, J. Fisiologia de sementes de plantas cultivadas. Piracicaba: FEALQ, 2005. 495p.

MOTERLE, L.M.; SCAPIM, C.A.; BRACCINI, A.L.; RODOVALHO, M.A.; BARRETO, R.R. Influência do estresse hídrico sobre o desempenho fisiológico de sementes de híbridos simples de milho-pipoca. Ciência e Agrotecnologia, Lavras, v.32, n.6, p.1810-1817, 2008.

PÍPOLO, A.E. Influência da temperatura sobre as concentrações de proteínas e óleo em sementes de soja (Glycine max (L.) Merrill). 2002. 128f. Tese (Doutorado)-Escola Superior de Agricultura "Luiz de Queiroz”, Universidade de São Paulo, Piracicaba, 2002.

SEDIYAMA, T.; PEREIRA, M.G.; SEDIYAMA, C.S.; GOMES, J.L.L. Cultura da soja: parte I. Viçosa, MG: UFV, 1993. 97p.

TAIZ, L.; ZEIGER, E. Fisiologia vegetal. 3.ed. Porto Alegre: Artmed, 2004. 613p.

VITTI, G.C.; CAMARGO, M.A.F.; LARA, C. Síntese de análise químicas em tecido vegetal. Piracicaba: USP, 2001. 89p. 